\title{
Promoting Students' Transitions to Successive VET Levels through Continuing Learning Pathways
}

\author{
Harm Biemans ${ }^{1}$ (D) Hans Mariën ${ }^{2}$ - Erik Fleur ${ }^{3}$. \\ Tanya Beliaeva ${ }^{3} \cdot$ Jan Harbers $^{4}$
}

Received: 12 October 2017 / Accepted: 4 March 2018 / Published online: 13 March 2018

(C) The Author(s) 2018, corrected publication March/2018

\begin{abstract}
Continuing learning pathways have been proposed as curriculum design solutions to reduce student drop-out rates and to promote their transitions to successive levels of the educational system. The present study aimed to compare the effects of a specific continuing learning pathway in Dutch VET (the Green Lyceum or GL, which combines a lower secondary pre-vocational school-based (VMBO) programme and a middle-management VET (MBO) programme in an integrated learning trajectory offered by agricultural (or 'green') VET institutes) with a more traditional route (a regular middle-management VET programme) in terms of students' learning performance at MBO level and their transitions to a higher professional bachelor programme (HBO). GL students more often obtained a MBO diploma at EQF level 4 in the nominal study time period than comparable students in terms of cognitive level in regular MBO. Moreover, former GL students more often proceeded with an HBO programme than comparable students coming from regular MBO. Finally, students coming from the GL less often opted for HBO programmes in the agricultural domain than comparable students coming from regular 'green' $\mathrm{MBO}$ and more often decided to start with programmes corresponding with other sectors. To conclude, the combination of design characteristics of these continuing learning pathways seems to promote students' transitions within the VET system and, thus, can inspire the design and implementation of comparable learning routes to solve transition problems.
\end{abstract}

Harm Biemans

harm.biemans@wur.nl

1 Education and Learning Sciences (ELS), Wageningen University \& Research, P.O. Box 8130, 6700 EW Wageningen, The Netherlands

2 IVA Education, Tilburg University, Warandelaan 2, 5037 AB Tilburg, The Netherlands

3 Department of Education, Culture, and Science, Executive Agency for Education (DUO), Rijnstraat 50, 2515 XP The Hague, The Netherlands

4 Terra Groningen, P.O. Box 17, 9700 AA Groningen, The Netherlands 
Keywords Continuing learning pathways · Transitions · Vocational education and training (VET) · Green lyceum

\section{Introduction}

One of the most prominent educational policy goals in countries throughout the world is that more students should reach higher educational levels (Keeley 2007; OECD 2010; Dutch Educational Council 2014). This goal is regarded as crucial, both for individuals and for society as a whole, to be able to deal with future challenges. To reach this goal, it is preferable that students are able to proceed from one educational level to the next in seamless learning pathways and that there are no artificial barriers between successive levels of the particular educational system (in this study the Vocational Education and Training, or VET, system) that hamper students' transitions and their individual competence development (Biemans et al. 2004, 2009, 2016).

In reality, however, transitions between successive VET levels often appear to be very problematic for many students (Biemans et al. 2013). In many countries, such transition problems between successive (VET) levels resulting in high student drop-out rates have been reported (e.g., Bradley 2008; Harris and Rainey 2012; Hoelscher et al. 2008; Catterall et al. 2014). Possible causes for these transition problems have been discussed extensively by Biemans et al. (2016) (see also the next section). A crucial issue in this regard is the lack of curriculum continuity and integration of successive educational levels.

To improve students' transitions and to prevent the high drop-out rates mentioned above, continuing learning pathways have been implemented in VET (and general education) systems around the world as curriculum design solutions (see Biemans et al. 2016). Continuing learning pathways can be defined as sequential educational programmes combined into a new integrated learning trajectory (Biemans et al. 2013). For example, in the Netherlands, the context of this particular study, many experiments have been initiated in the last decade by governmental policy (e.g., Dutch Ministry of Education, Culture, and Science 2005; Dutch Educational Council 2014) to design continuing learning pathways and, thus, to connect various levels of the VET system (i.e., lower secondary pre-vocational school-based programmes (VMBO), middle-management VET programmes (MBO) and higher professional bachelor programmes (HBO) (see Fig. 1)).

A crucial question in this regard is whether such continuing learning pathways do indeed promote students' learning performance in terms of acquired diplomas and their transitions to successive educational levels (upward educational mobility). The present study aimed to compare the effects of a specific continuing learning pathway in Dutch VET (the so-called Green Lyceum or GL, which combines a VMBO programme and a MBO programme in an integrated learning trajectory offered by agricultural (or 'green') VET institutes - see also Fig. 1) with a more traditional route (a regular middle-management VET (MBO) programme) in terms of students' learning performance at the MBO level and their transitions to HBO. In other words, this research aimed to shed light on the question whether students' transitions to HBO (with performance at MBO level as crucial precondition) can be promoted through continuing learning pathways encompassing VMBO and $\mathrm{MBO}$. 


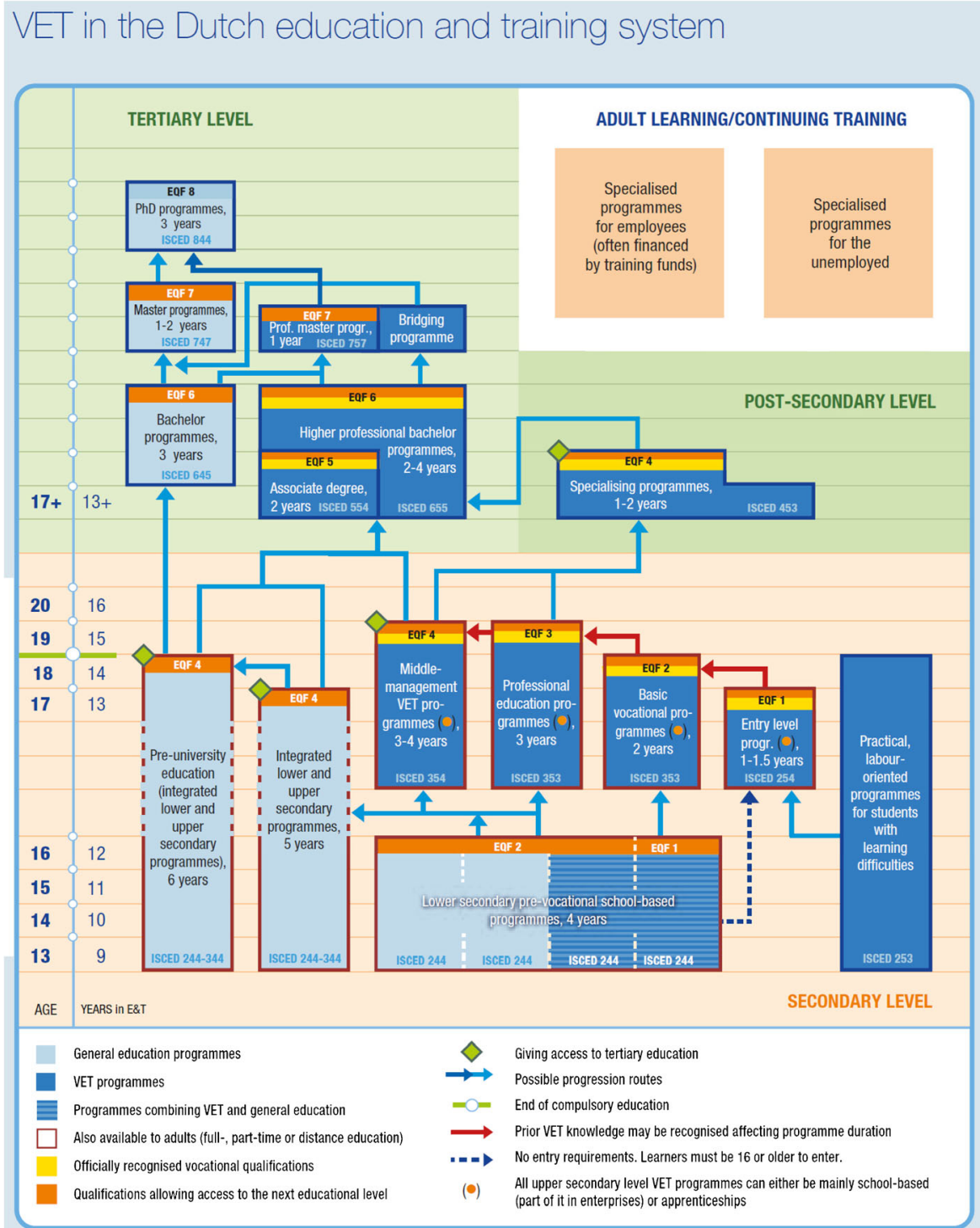

NB: ISCED-P 2011

Source: Cedefop and ReferNet Netherlands.

Fig. 1 VET in the Dutch education and training system (Cedefop 2016)

This study can be considered as a follow-up study to our research described in the article "Students' Learning Performance and Transitions in Different Learning Pathways to Higher Vocational Education" published earlier in Vocations and Learning (Biemans et al. 2016). This previous article focused on the effects of this particular continuing learning pathway on students' learning performance at the VMBO level and their transitions to the MBO level (in other words, effects of the first phase of this learning pathway). The present study, however, aimed to research the 
effects of the second phase of the learning pathway on students' learning performance and transitions in the VET system. In this respect, the present study is a crucial followup study since it focuses on the effects at the end of the particular continuing learning pathway on students' study careers, and, thus, provides additional information on the value of such learning pathways with their underlying educational design principles as described in the section "The Green Lyceum as Critical Example of a Continuing Learning Pathway". First, however, theoretical background notions on students' transition problems in VET and continuing learning pathways as possible solutions will be presented building on the previous article (see also Biemans et al. 2016). After describing the GL in terms of design characteristics and theoretical embedding, the results of previous research on effects of the GL will be summarized. Next, method and results of the present study will be presented, followed by a discussion section including an agenda for future research.

\section{Transition Problems in VET and Possible Interventions}

As mentioned above, many students experience problems when their transition between successive levels of the VET system is concerned (but also in other segments of the educational system). This phenomenon has been analysed and described in the international literature on the permeability of educational systems (e.g., Bathmaker and Thomas 2009; Catterall et al. 2014; Gorard et al. 2006; Harris and Rainey 2012; Hoelscher et al. 2008; Watson 2006).

One of the key aspects of permeability of educational systems is the "capacity of education and training systems to enable learners to access and move among different pathways (programmes, levels) and systems" (Cedefop 2014, p. 193). In many cases, the permeability of educational systems is suboptimal and even if there are hardly any institutional barriers between successive levels, it is often very difficult for students to relate and integrate the educational programmes of the different levels or to adjust to the particular requirements of the new programme. Such transition problems may lead to highly stressful experiences of the students and feelings of disconnection with their new educational programme and learning environment (Mulder 2016), resulting in less successful study careers and substantial drop-out rates (Biemans et al. 2013; Wheelahan 2008).

Students' transition problems have been identified in the Dutch VET system as well as significant issues that need to be tackled (see e.g. Mulder and Cuppen 2016; Schouten and Westerhuis 2014; Sneyers and De Witte 2016; Van den Berg et al. 2017). To illustrate, in the Netherlands, about $17 \%$ of the former MBO students entering an HBO programme appears to drop out during or immediately after their first HBO study year. In general, these students do not return to an HBO programme at a later stage so their drop-out from the educational system can be considered as final (SCP 2016). Significant drop-out rates have been documented earlier in the VET system between the successive levels VMBO and $\mathrm{MBO}$ as well (see e.g., AOC Council 2012; Biemans et al. 2013, 2016 for statistics for Dutch agricultural VET and e.g., Kuijpers 2014 for Dutch VET in general). These drop-out rates have serious negative consequences for the individual students concerned but also for educational organisations, businesses and other possible employers, and society. 
Student drop-out might be caused by a variety of student factors and external factors in the (educational) environment of the students. As possible student factors, Mulder and Cuppen (2016) and Sneyers and De Witte (2016) mentioned e.g., gender, family background, age, financial circumstances, learning performance in previous and present education, degree of social integration, and socio-psychological factors. In addition, Biemans et al. (2016) also identified deficiencies and mismatches in students' learning competencies, motivation, cognitive level, and expectations and perceptions of followup educational programmes and their future careers as potential causes of drop-out.

Regarding possible external factors, Sneyers and De Witte (2016) mentioned e.g., characteristics of the region (such as availability of companies in a particular vocational domain which might influence the student's choices), quality of the educational organisation, and the living environment of the student. Sharp selection and admission criteria (as adopted by possible follow-up educational programmes) and lacking career orientation, guidance, and mentoring (as provided by the student's present educational institute) might play a role as well (Kuijpers et al. 2011; Kuijpers 2014; Winters 2012). Moreover, Biemans et al. $(2013,2016)$ concluded that the degree to which successive educational programmes are attuned in terms of learning environments, didactics, and learning contents is crucial to facilitate students' transitions (see also Jäppinen and Maunonen-Eskelinen 2012). In this article, the focus will be especially on this last factor and on interventions aimed at solving problems of discontinuity and disintegration as mentioned above. Generally, these curriculum redesign interventions are initiated by cooperating educational organisations representing successive VET levels to improve students' transitions (see Sneyers and De Witte (2016) for an extensive literature review on such interventions).

An important recent trend in the educational landscape in general and the VET system in particular is the design and implementation of so-called continuing learning pathways. Continuing pathways are "characterised by curriculum continuity in particular competence areas or subjects [such as mathematics, physics, and Dutch language] lasting several years, and encompassing more than one qualification level" (e.g., $\mathrm{VMBO}$ and MBO) (Biemans et al. 2013, p. 109). In this regard, the concept of competence can be defined as "the integration of knowledge, skills, and attitudes needed to perform adequately in specific professional situations" (Biemans et al. 2013, p. 108-109).

According to Biemans et al. 2016, p. 316), "the aim of these continuing pathways is to ensure curriculum continuity [and integration] of successive educational programmes and, thus, to promote and streamline students' knowledge and skill acquisition and competence development"(cf. Brockmann et al. 2008; Clarke and Winch 2007; Putnam and Borko 2000). In this way, so-called competence progression models for specific content domains can be implemented to ensure students' continuing competence development. For example, Lilleväli and Täks (2017, p. 3) elaborated on the concept of a competence progression model within the context of entrepreneurship education (or EE) as "a step-by-step advancement in various contexts and with learning outcomes and roles of EE throughout the education system" (see also Lackéus 2015; Rasmussen and Nybye 2013).

The issue of seamless educational pathways, however, also deserves some nuance. It might not always be possible to develop such continuing learning pathways given practical circumstances or this might even be undesirable from a boundary crossing 
point of view: Students can also benefit from differences in culture between school and work, e.g., during apprenticeships (cf. Akkerman and Bakker 2012).

\section{The Green Lyceum as Critical Example of a Continuing Learning Pathway}

In the Netherlands, the first Green Lyceum (GL) started in 2007 as a continuing learning pathway in VET, combining a lower secondary pre-vocational school-based programme (VMBO) and a middle-management VET programme (MBO; cf. EQF level 4 - see Cedefop 2016 (see also Fig. 1)). At this moment, the GL is offered by 12 schools of 6 agricultural VET institutes, which explains the "green" in "Green Lyceum". The GL can be considered as critical example of a continuing learning pathway for other ongoing experiments with such learning routes in other domains (such as technology and health care) within Dutch VET, which are more or less comparable in terms of educational design characteristics (see e.g. Imandt et al. 2016).

The GL specifically aims at students who have ambitions to proceed with a higher professional bachelor programme (HBO) after finishing their secondary education (see also Biemans et al. 2016 and Fig. 1). In other words, students' transition to higher professional bachelor programmes is a central goal from the very beginning of their learning pathway. These students can be characterized as students with relatively high learning capacities as indicated by the advice for follow-up education that they receive at the end of primary education (i.e., EQF 4 level; see also Fig. 1), and who do not appear to find a suitable learning environment in regular secondary education that corresponds with their specific interests (a preference for a relatively high cognitive level of education combined with an orientation towards vocational practice as shown by their willingness to engage in practical assignments) (cf. Jäppinen and MaunonenEskelinen 2012). A main assumption behind the design of continuing learning pathways like the GL is that students with these specific characteristics comprise a significant student category, whose preferences are not sufficiently being acknowledged and served in regular secondary (general and vocational) education (see also Biemans et al. 2016; Jäppinen and Maunonen-Eskelinen 2012; Van den Berg 2013).

The GL offers a theoretical and broad vocation-oriented preparation for follow-up HBO programmes through an integrated, continuing learning pathway combining VMBO and MBO programmes. The GL consists of a 6-year learning trajectory (instead of the regular 7 years) with options for deepening, broadening, and accelerating the educational programme (e.g., acceleration from 6 to 5 years; cf. Jäppinen and Maunonen-Eskelinen 2012). As part of the GL pathway, students can obtain a $\mathrm{VMBO}$ diploma and a $\mathrm{MBO}$ diploma at EQF level 4, which is required to enter HBO (see also Fig. 1 and Cedefop 2016). These diplomas correspond with the required learning outcomes of regular VMBO and MBO level 4 programmes and, thus, the GL programme can neither be regarded as easier nor as narrower than the regular programmes.

The combination of GL design characteristics can be described in more detail as follows (see also Biemans et al. 2016):

1. GL is an integrated 6-year learning route, combining a $\mathrm{VMBO}$ and an $\mathrm{EQF}$ level 4 MBO programme: 
- Subjects are taught following continuing learning pathways, in which MBO components descend in the first (VMBO) phase of the trajectory. Based on the original VMBO and MBO programmes, a new GL curriculum had been designed (by joint teams of VMBO and MBO teachers per subject) in which content elements from both programmes were integrated into one instructional method to promote a continuing learning process without repetition or knowledge gaps and to make acceleration possible. Integration of content elements from these successive educational levels proved to be a more effective approach in terms of students' learning performance and their school satisfaction, school wellbeing, and motivation for school than the original learning pathway in which VMBO and MBO content elements, instructional methods, and teacher teams were strictly separated (see for more details Biemans et al. 2013);

- Education is intertwined with an integral and continuing practical component. During the entire GL trajectory, students work on assignments that stimulate them to apply theoretical knowledge in daily life and vocation-oriented contexts. Moreover, from third grade on, students do internships in companies and other organizations;

- From first grade on, students build their own portfolio. In this portfolio, students document their own study results, competence development, motives, and qualities. In the second half of the GL programme, students also explore different vocational contexts in relation to their own preferences and competencies in order to choose a specific follow-up HBO programme and corresponding career. The portfolio is taken into account in the intake carried out by the particular HBO institute.

2. GL is primarily aimed at preparing students for higher professional bachelor programmes in the full spectrum of HBO sectors (a broad vocational orientation instead of a narrow focus on the agricultural domain; in this regard, the 'green' in 'Green Lyceum' is a bit confusing):

- GL aims at students with ambitions and cognitive capacities to proceed with an HBO programme and who have developed the following generic competencies to a relatively high extent: practice-oriented, problem-solving, entrepreneurial, inquiryoriented, independent, and socially competent. To determine whether students meet these criteria, an intake with individual GL candidates takes place before they can enter the programme. In the selection process, the advice for a specific secondary education level as provided by the student's primary school is taken into account as well (criterion: general secondary education at EQF 4 level (HAVO));

- General theoretical subjects (e.g., mathematics, physics, Dutch and English language) are attuned to HBO programmes with respect to content and required theoretical level (in this regard, the GL programme is comparable with general secondary education at EQF 4 level, which prepares for $\mathrm{HBO}$ programmes in all domains). The vocation-oriented parts of the GL trajectory cover different vocational domains with specific attention for new developments, depending on the individual student's preferences for specific HBO programmes;

- There is continuing and systematic attention for career orientation and guidance in the broad spectrum of vocational sectors (see also the previous aspect) aimed at transition to HBO. The student's internships and practical assignments in various 
vocational domains and their visits to different $\mathrm{HBO}$ programmes play an important role in this orientation process;

- Pedagogy is attuned to the students' characteristics: activating, focusing on student cooperation, and stimulating self-regulated learning. Assignments are meant to develop their related competencies and students are increasingly held responsible for their own learning process. In this way, the GL programme aims at developing learning competencies (e.g., planning, organizing) and research competencies (e.g., analyzing and problem solving).

3. GL is a practice-oriented learning route:

- The learning pathway includes real-life projects and assignments of increasing complexity in contextualized and authentic learning environments, in which students develop competencies in various practical, vocation-oriented contexts and domains (as described above). In the first GL study years, this concerns projects and assignments that are aimed at developing learning competencies such as collaborating, planning, and organizing. Later on, more complex projects and internship assignments are introduced focusing on research and entrepreneurial competencies (including relevant skills, knowledge, and attitudes);

- This learning in practice (including internships) takes place in different companies and organizations in the region in which the GL institute is located to enable individual students to discover which professional context corresponds with their own preferences. In the fifth and sixth GL year, students do an internship at a company accredited for the MBO EQF4 diploma. In this regard, an international internship is an option as well.

4. GL offers tailor-made, adaptive education:

- The specific content of the educational programme is attuned to the talents, interests, and (study) career of the individual student. Key words in this respect are: deepen, broaden, and accelerate. Depending on the individual student's progression and preferences during the programme, choices can be made to focus more on specific content, to include other possible vocational contexts, and/or to speed up the learning process;

- The programme fosters both theory-based learning and learning in practice. In this regard, there is no clear-cut distinction: Theory is applied in practical contexts as well;

- Education makes full use of the possibilities offered by e-learning tools. Students use an electronic learning environment containing study guides for the various subjects, assignments, and study content. Moreover, students' learning results are stored in the electronic learning environment and guidelines for career orientation and guidance, developing the portfolio, and supervision of internships are included.

This combination of characteristics regarding target group, educational level and design, and pedagogical approach defines the GL trajectory and makes it different from more traditional pathways to $\mathrm{HBO}$ such as regular MBO and HAVO. 


\section{Previous Research on Effects of the Green Lyceum}

In a previous study, Biemans et al. (2016) already reported on effects of the GL (with the specific design characteristics as described in the previous section) in terms of students' learning performance and their transitions to a successive VET level. Because of limited numbers of students that had finished the full GL programme at that time, however, this previous study only focused on the first (VMBO) phase of this educational programme: GL students' learning performance in the first phase and their transitions to the second (MBO) phase were compared with the learning performance and transitions of a group of regular VMBO students (comparable with the GL students in general cognitive ability level - and, thus, in this regard the top segment of the regular VMBO students -, gender, and year of examination) (see for more details on the design of this study Biemans et al. 2016).

Students in the GL group and the regular VMBO group appeared to have comparable mean final exam scores for $4 \mathrm{VMBO}$ core subjects (Mathematics, English language, Dutch language, and Biology), but GL students achieved this performance level one year earlier because of the acceleration in the GL programme (see also Jäppinen and Maunonen-Eskelinen 2012; Harris and Rainey 2012; Hoelscher et al. 2008). Moreover, compared with the regular VMBO students, the percentage of GL students that proceeded with MBO after obtaining their VMBO diploma was higher (see also Van den Berg 2013). With respect to these effects on students' learning performance and their transitions to $\mathrm{MBO}$, no differences were found between the various GL institutes: apparently, students from the various GL institutes did benefit to the same extent from their educational programme (cf. Biemans et al. 2013).

To conclude, Biemans et al. (2016) showed that the GL with the combined design characteristics was more effective for this specific target group of students with a relatively high cognitive ability level than the regular VMBO pathway in terms of students' learning performance and their transitions to $\mathrm{MBO}$ but, at that point, the question remained whether the GL is also more effective in promoting students' transitions to higher professional bachelor programmes (HBO), which could be considered as the ultimate goal of these continuing learning pathways (see also Bradley 2008; Catterall et al. 2014; David 2010; Gorard et al. 2006; Hayward 2006; Watson 2006). Therefore, the present study, which was already announced by Biemans et al. (2016), was carried out as follow-up research to examine whether the GL does promote students' transitions to HBO, as the next educational level in the Dutch VET system. As such, this study should shed more light on the potential of continuing learning pathways to reduce students' transition problems between successive educational levels and to foster their transition to higher (vocational) education.

\section{Study Aim and Questions}

In line with the above-mentioned goal of continuing learning pathways, this study aimed to examine whether such learning trajectories (in this case the GL with the combined design characteristics described earlier) did lead to more students finishing MBO with a diploma at EQF level 4 and whether they did promote transitions of students from MBO to HBO as successive levels in the Dutch VET system. Therefore, in the present study, the effects of the GL were compared with the effects of a more 
traditional learning pathway to HBO (i.e., a regular middle-management VET programme or MBO in the 'green' domain). Thus, as opposed to the previous study (Biemans et al. 2016) that focussed on the first (VMBO) phase of the GL trajectory, this study was aimed at examining the effects of the second (MBO) phase of this continuing learning pathway. In this regard, it should be considered as a follow-up study, in which three additional research questions were answered:

- Do regular $\mathrm{MBO}$ and GL programmes differ in percentages of students that obtained a MBO diploma at the highest level (EQF level 4) (RQ1)?

- Do regular MBO and GL programmes differ in percentages of students that proceeded with an $\mathrm{HBO}$ programme after obtaining their $\mathrm{MBO}$ diploma (RQ2)?

- Do regular MBO and GL programmes differ with respect to the nature of HBO programmes that are chosen by the students after obtaining their MBO diploma (RQ3)?

\section{Method}

\section{Participants and Design}

To answer the various research questions, the first substantial cohorts of students from two educational institutes that could have graduated from the GL learning pathway were contrasted with a group of comparable regular MBO students from the same two agricultural VET institutes. These two organisations were the first Dutch institutes offering a GL trajectory. The other institutes with a GL learning pathway did not have substantial numbers of graduates at the time of the study. The GL group consisted of 86 students (52 male and 34 female students; institute 1 with 2 successive cohorts: $N=22$ and $N=43$ and institute 2 with 1 cohort: $N=21)$.

The group of regular MBO students $(N=86)$ was characterised by a comparable group composition matched in terms of cognitive level (as indicated by their mean national VMBO final exam score for the core subjects Dutch language, English language, Mathematics, and Biology), gender, institutes, and cohorts. All students in this group had started at the highest MBO EQF level 4, which is identical to the GL MBO level. For all students from both groups, the nominal period of study time for their learning pathway was taken as the starting point. This meant that students from both groups could have obtained their MBO diploma at EQF level 4 (which is required to enter HBO) in the same years 2015 or 2016, depending on the particular cohort. At this point, it should be noted that, because of the acceleration in the GL trajectory, the regular MBO students had more time to finish their MBO learning pathway (see section "The Green Lyceum as Critical Example of a Continuing Learning Pathway"). The composition of both groups is described in Table 1 .

\section{Dependent Variables and Data Analysis}

To answer the first research question, percentages of students that either did or did not obtain a MBO diploma (at EQF level 4 in the nominal period of time) were calculated for both groups. In addition, to examine research question 2 regarding students' transitions 
Table 1 Composition of the GL group and the regular MBO comparison group in terms of their cognitive level (mean national VMBO final exam score for the core subjects Dutch language, English language, Mathematics, and Biology) and their gender (Male; Female)

\begin{tabular}{llrr}
\hline Mean VMBO final exam score & Gender & GL & Regular MBO \\
\hline$<6$ & M & 13 & 13 \\
& F & 7 & 7 \\
$6-6.5$ & M & 15 & 15 \\
& F & 9 & 9 \\
$6.5-7$ & M & 13 & 13 \\
& F & 7 & 8 \\
$7-7.5$ & M & 7 & 7 \\
$7.5-8$ & F & 9 & 8 \\
& M & 3 & 4 \\
$>8$ & F & 2 & 2 \\
& M & 1 & 0 \\
Total & F & 0 & 0 \\
\hline
\end{tabular}

to higher professional bachelor programmes, percentages of students that either did or did not proceed with an $\mathrm{HBO}$ programme after obtaining their MBO diploma were calculated for GL and regular MBO programmes. Finally, with respect to the third research question, percentages of students that proceeded with an HBO programme either or not in the 'green' domain were compared. Percentages of students from the GL group and the regular MBO group were compared through Chi-Square tests using a SPSS Crosstabs procedure. Thus, given the (nominal) data measurement level resulting in percentages, non-parametric statistics were used (cf. Biemans et al. 2016).

\section{Results}

Regarding the percentages of students that obtained a MBO diploma at the highest EQF level 4 (a crucial precondition for former MBO students to be allowed to enter an HBO study programme) (RQ1), the GL group appeared to score significantly higher than the

Table 2 Percentages of GL students and regular MBO students that either did or did not obtain a MBO diploma at EQF level 4 in the nominal period of study time

\begin{tabular}{|c|c|c|c|c|}
\hline & & \multicolumn{2}{|c|}{ MBO diploma(EQF level 4) } & \multirow[t]{2}{*}{ Total } \\
\hline & & No & Yes & \\
\hline & GL & 9.3 & 90.7 & 100.0 \\
\hline & Regular MBO & 31.4 & 68.6 & 100.0 \\
\hline Total & & 20.3 & 79.7 & 100.0 \\
\hline
\end{tabular}


Table 3 Percentages of students that either did or did not proceed with an HBO programme after obtaining their MBO diploma for the GL group and the regular MBO group

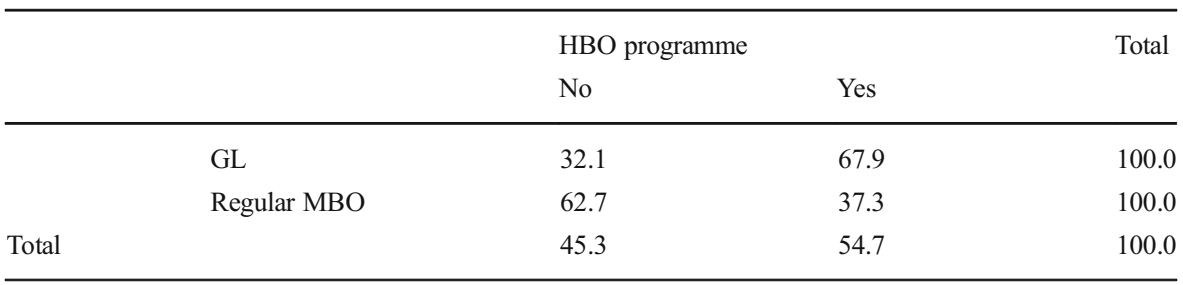

Table 4 Percentages of students that either did or did not proceed with an HBO programme in the 'green' domain for the GL group and the regular MBO group

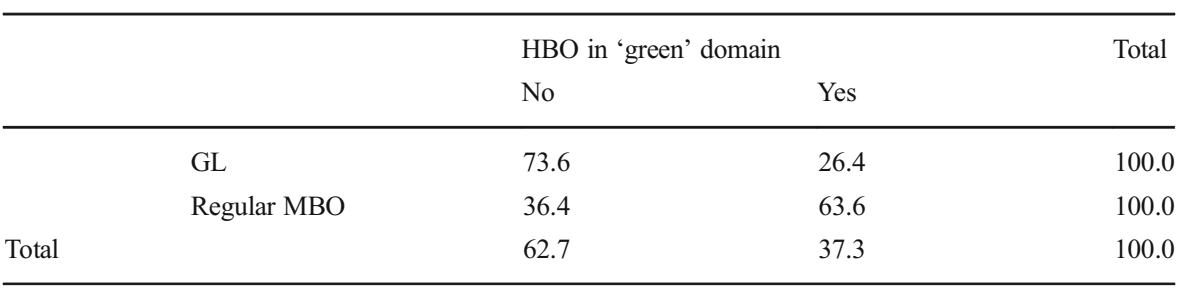

regular MBO group $\left(\mathrm{X}^{2}(1)=11.56 ; p \leq 0.001\right)$ : Students in the GL pathway more often obtained a MBO diploma at EQF level 4 in the nominal period of study time than comparable students in regular MBO (see Table 2). Students in regular MBO more often obtained MBO diplomas at lower EQF levels or did not obtain a MBO diploma at all.

With respect to the percentages of students that proceeded with an HBO programme after obtaining their MBO diploma (RQ2), again the GL group scored significantly higher than the regular MBO group $\left(\mathrm{X}^{2}(1)=12.75 ; p \leq 0.001\right)$ : Students coming from the GL pathway more often proceeded with an $\mathrm{HBO}$ programme than comparable students coming from regular MBO (see Table 3). Students coming from regular MBO, on the other hand, more often decided to enter the labour market after obtaining their diploma and not to proceed with an HBO programme.

Regarding the percentages of students that proceeded with an HBO programme in the agricultural domain (RQ3), the GL group appeared to score significantly lower than regular MBO group $\left(\mathrm{X}^{2}(1)=9.21 ; p \leq 0.005\right)$ : Students coming from the GL less often opted for HBO programmes in the 'green domain' than comparable students coming from regular 'green' MBO (see Table 4): Former GL students more often decided to start with HBO programmes corresponding with other sectors, e.g., management or communication.

\section{Conclusions and Discussion}

The present study aimed to shed light on the question whether students' transitions to successive levels in the VET system can be promoted through continuing learning pathways (in this case the Green Lyceum or GL). Based on the results, the GL appeared to be more effective than the regular middle-management VET pathway (MBO level 
EQF4) in promoting students' transitions to a higher professional bachelor programme (HBO) (with a MBO diploma at EQF level 4 being a crucial precondition). In other words, it seems to be possible to improve students' transitions between successive VET levels through continuing learning pathways such as the GL (at this point, it should be noted that it is also possible for GL students to switch to regular MBO if necessary and to proceed with an HBO programme after graduation). Comparable continuing learning pathways could be a curriculum solution to facilitate and support students' transitions to higher educational levels in other contexts and countries as well (see also Bradley 2008; Catterall et al. 2014; David 2010; Gorard et al. 2006; Hayward 2006; Watson 2006). Of course, additional research is needed to determine whether this conclusion is justified.

With respect to the GL, the combination of design characteristics of this continuing learning pathway seems to be effective to promote students' transitions to successive VET levels. In this regard, several characteristics seem to be of crucial importance. Compared with the regular MBO pathway, the GL is especially designed for a specific target group of students: Students with a relatively high cognitive ability level combined with a preference for practical, work-related assignments, and who have ambitions to proceed with an HBO programme after their GL trajectory. The traditional routes for these students would either be a regular $\mathrm{MBO}$ programme after obtaining a diploma of a lower secondary pre-vocational school-based programme (VMBO) or regular general secondary education (5 years/EQF 4, or HAVO) (see Fig. 1). The present study seems to support the assumption that the preferences and competencies of these students are not sufficiently being acknowledged and served in regular VMBO and MBO (see also Biemans et al. 2016; Van den Berg 2013). Thus, the specific selection of this category of students for the GL seems to be beneficial for them and to improve their chances to enter an HBO programme, as compared with the traditional VMBO-MBO route (see also Jäppinen and Maunonen-Eskelinen 2012).

Having entered the GL, the integration of VMBO and MBO elements resulting in an acceleration of the learning trajectory as a whole appears to be effective for these students in terms of their learning performance and motivation (see also Biemans et al. 2013). Because of their relatively high cognitive ability level, the regular pathway from VMBO to MBO seems to be not challenging enough for these students, which could lead to underachievement or even drop-out. In this regard, the required cognitive level for the GL, which is comparable with regular general secondary education (HAVO), seems to be more attuned to the capacities of these students and also to the required theoretical level in HBO.

The HAVO curriculum, on the other hand, lacks the practical orientation of the GL and also of MBO, which is less appealing for this category of students. In this way, the GL as a practice-oriented learning route seems to offer a more suitable preparation for the vocational aspects of HBO, as compared with HAVO with its theoretical focus. In the GL, learning through practical assignments, vocation-oriented projects, and internships already takes a prominent position, which might give the students a better starting position in HBO when their orientation towards vocational practice is concerned (cf. Billett 2001; Griffiths and Guile 2003).

Therefore, one could conclude that the interests and competencies of this specific group of students are best served by an educational programme such as the GL that combines the required cognitive level of regular general secondary education (HAVO) and the orientation towards vocational practice of a regular middle-management VET programme (MBO). 
The GL, being primarily aimed at preparing students for $\mathrm{HBO}$, pays extensive attention to the development of learning and research competencies, which are essential for study success in HBO. Specific competencies such as finding and processing information, presenting, doing research, reflecting, analyzing, and using ICT are being developed through tailormade, adaptive education supported by systematic career orientation and guidance, which are not always that visible in the traditional learning pathways to HBO (cf. Kuijpers 2014).

Another conclusion from the present study is that students coming from the GL less often chose for HBO programmes in the agricultural domain than comparable students coming from regular 'green' MBO. This finding is not surprising because broad orientation on vocational sectors (instead of a narrow focus on agriculture) is also one of the crucial GL design characteristics. The educational programme is organised based on a range of possible follow-up studies. This broad focus makes it possible for GL students to choose from a variety of HBO programmes (not only 'green' educational programmes but also HBO programmes in economics, behaviour and society, health care, education, technical sciences, etc.) and is in line with the development of generic competencies throughout the programme in preparation for a follow-up HBO study. In the second half of their GL programme, students focus more on specific HBO study domains and are prepared accordingly through internships and assignments in those domains. Thus, students' future plans and possible choices for a particular follow-up HBO study are taken into account: In their last GL study years, the (practical and cognitive) content of their educational programme is attuned to the domain of their preferred successive $\mathrm{HBO}$ programme (to a higher extent than possible in regular MBO programmes). On the other hand, students also are expected to achieve all expected learning outcomes corresponding with their MBO EQF4 diploma. In this way, students are well-prepared to enter the labor market if they decide not to proceed with an HBO study programme.

To summarize, based on the findings of the present study, continuing learning pathways such as the GL seem to promote students' transitions to higher professional bachelor programmes. Whether students who have graduated from the GL and have entered a higher professional bachelor programme are also more successful in their HBO study careers than students coming from the more traditional pathways VMBO-MBO and HAVO (the real 'proof of the pudding' since preparation for HBO is the ultimate goal of these continuing learning pathways) requires further investigation. Therefore, in a follow-up study, former GL students' learning performance in $\mathrm{HBO}$ will be compared with the learning performance of students coming from the other routes. In this regard, students' study career patterns and drop-out rates in HBO will be studied as well. Moreover, their study experiences in HBO will be examined and compared. Key issues in this regard are how motivated students are for their present HBO study and how they rate their HBO study success. Additionally, students will be asked to rate their own previous education (the continuing learning pathway GL or one of the traditional learning routes respectively) in terms of theoretical content level, level of practical preparation, teacher quality, focus on learning competencies, and career orientation and guidance. Results of this follow-up study are expected to be reported in the forthcoming years and should shed more light on the longer term effects of these continuing learning pathways and lead to further recommendations for educational practice how lower and higher VET levels could be more attuned in terms of educational design.

Open Access This article is distributed under the terms of the Creative Commons Attribution 4.0 International License (http://creativecommons.org/licenses/by/4.0/), which permits unrestricted use, distribution, and reproduction in any medium, provided you give appropriate credit to the original author(s) and the source, provide a link to the Creative Commons license, and indicate if changes were made. 


\section{References}

Akkerman, S. F., \& Bakker, A. (2012). Crossing boundaries between school and work during apprenticeships. Vocations and Learning, 5(2), 153-173.

AOC Council (2012). Sector plan AOCs 2012-2015 Sempervivum. Ede: AOC Council.

Bathmaker, A. M., \& Thomas, W. (2009). Positioning themselves: An exploration of the nature and meaning of transitions in the context of dual sector FE/HE institutions in England. Journal of Further and Higher Education, 33(2), 119-130.

Biemans, H., Nieuwenhuis, L., Poell, R., Mulder, M., \& Wesselink, R. (2004). Competence-based VET in the Netherlands: Background and pitfalls. Journal of Vocational Education and Training, 56(4), 523-538.

Biemans, H., Wesselink, R., Gulikers, J., Schaafsma, S., Verstegen, J., \& Mulder, M. (2009). Towards competence-based VET: Dealing with the pitfalls. Journal of Vocational Education and Training, 61(3), 267-286.

Biemans, H. J. A., De Bruijn, E., Den Boer, P. R., \& Teurlings, C. C. J. (2013). Differences in design format and powerful learning environment characteristics of continuing pathways in vocational education as related to student performance and satisfaction. Journal of Vocational Education and Training, 65(1), $108-126$.

Biemans, H., Mariën, H., Fleur, E., Tobi, H., Nieuwenhuis, L., \& Runhaar, P. (2016). Students' Learning Performance and Transitions in Different Learning Pathways to Higher Vocational Education. Vocations and Learning, 9(3), 315-332.

Billett, S. (2001). Knowing in practice: Re-conceptualising vocational expertise. Learning and Instruction, 11, 431-452.

Bradley, D. (2008). Review of Australian higher education: Final report. Canberra: Commonwealth of Australia.

Brockmann, M., Clarke, L., Méhout, P., \& Winch, C. (2008). Competence-based vocational education and training (VET): The cases of England and France in a European perspective. Vocations and Learning: Studies in Vocational and Professional Education, 1, 227-244.

Catterall, J., Davis, J., \& Yang, D. F. (2014). Facilitating the learning journey from vocational education and training to higher education. Higher Education Research and Development, 33(2), 242-255.

Cedefop (2014). Terminology of European education and training policy: A selection of 130 terms (2nd ed.). Luxembourg: Publications Office of the European Union.

Cedefop (2016). Spotlight on VET the Netherlands. Thessaloniki: Cedefop.

Clarke, L., \& Winch, C. (2007). Vocational education: International approaches, developments and systems. London: Routledge.

David, M. (Ed.). (2010). Improving learning by widening participation in higher education. London: Routledge.

Dutch Educational Council (2014). Overgangen in het onderwijs [Transitions in education]. The Hague: Dutch Educational Council.

Dutch Ministry of Education, Culture, and Science (2005). VMBO: het betere werk [lower secondary prevocational school-based programmes (VMBO): Work of higher quality]. The Hague: Ministry of Education, Culture, and Science.

Gorard, S., Smith, E., May, H., Thomas, L., Adnett, N., \& Slack, K. (2006). Review of widening participation research: Addressing the barriers to participation in higher education. A report to HEFCE. York: University of York, Higher Education Academy and Institute for Access Studies.

Griffiths, T., \& Guile, D. (2003). A connective model of learning: The implications for work process knowledge. European Educational Research Journal, 2(1), 56-73.

Harris, R., \& Rainey, L. (2012). Learning pathways between and within vocational and higher education: Towards a typology? Australian Educational Researcher, 39, 107-123.

Hayward, G. (2006). Participation, progression and success in vocational learning: A quantitative analysis of system performance. London: Learning and Skills Research Centre.

Hoelscher, M., Hayward, G., Ertl, H., \& Dunbar-Goddet, H. (2008). The transition from vocational education and training to higher education: A successful pathway? Research Papers in Education, 23(2), 139-151.

Imandt, M., Van den Berg, E., Heyma, A., Mulder, J., Schipperheyn, R., Hermanussen, J., Groot, A., Petit, R., Glaudé, M., Pater, C., \& Van der Meijden, A. (2016). We zijn begonnen! Tweede meting monitor Vakmanschap- en technologieroutes [We have started! Second assessment monitor craftsmanship and technology routes]. Amsterdam: SEO Economisch Onderzoek. 
Jäppinen, A.-K., \& Maunonen-Eskelinen, I. (2012). Organisational transition challenges in the Finnish vocational education - Perspective of distributed pedagogical leadership. Educational Studies, 38(1), 39-50.

Keeley, B. (2007). Human capital. How what you know shapes your life. Paris: OECD.

Kuijpers, M. A. C. T. (2014). Doorstroom VMBO-MBO [Transition lower secondary pre-vocational schoolbased programmes (VMBO) - upper secondary VET programmes (MBO)]. NRO Call for proposals Green Education Research. Den Haag: Dutch Organisation for Scientific Research (NWO).

Kuijpers, M., Meijers, F., \& Gundy, C. (2011). The relationship between learning environment and career competencies of students in vocational education. Journal for Vocational Behavior, 78(1), 21-30.

Lackéus, M. (2015). Entrepreneurship in education. What, why, when, how. Entrepreneurship360 and OECD. Retrieved from: www.schooleducationgateway.eu/downloads/entrepreneurship/40.1\%20OECD\%20 (2014)_BGP_Entrepreneurship\%20in\%20Education.pdf .

Lilleväli, U., \& Täks, M. (2017). Competence models as a tool for conceptualizing the systematic process of entrepreneurship competence development. Education Research International (Special issue Entrepreneurship education with impact: Opening the black box). Retrieved from: https://doi. org/10.1155/2017/5160863.

Mulder, J. (2016). Doorstroom MBO - HBO: studenten aan het woord. Over studiekeuze, verwachtingen en beleving [Transition MBO-HBO: Student stories. On study choice, expectations, and perception]. Den Bosch: ECBO.

Mulder, J., \& Cuppen, J. (2016). MBO-studenten die uitvallen op het HBO: wie zijn ze en waar vallen zij uit? Analyse van studentenstromen over periode 2005-2015 [MBO students who drop out in HBO: Who are they and when do they drop out? Analysis of student streams in the period 2005-2015]. Den Bosch: ECBO.

OECD (2010). Education of a glance. Paris: OECD.

Putnam, R. T., \& Borko, H. (2000). What do new views of knowledge and thinking have to say about research on teacher learning? Educational Researcher, 29, 4-15.

Rasmussen, A., \& Nybye, N. (2013). EE: Progression model. Odense C, Denmark: The Danish Foundation for Entrepreneurship - Young Enterprise. Retrieved from: www.ffe-ye.dk/media/44723/Progressionmodel-English.pdf .

Schouten, R., \& Westerhuis, A. (2014). Doorstroom van MBO naar HBO [Transition from MBO to HBO]. Presentation at the SK conference, May 22, Bunnik, The Netherlands.

SCP (2016). Wikken en wegen in het hoger onderwijs [Considerations in higher education]. The Hague: SCP.

Sneyers, E., \& De Witte, K. (2016). Doorstroom MBO-HBO en uitval in het HBO. Evidence-based aanbevelingen [Transition $\mathrm{MBO}-\mathrm{HBO}$ and drop-out in HBO. Evidence-based recommendations]. Den Bosch: ECBO.

Van den Berg, N. (2013). Doorstroom tussen groen VMBO en MBO. Onderzoek naar relevante factoren en sturingsmogelijkheden [Transition between agricultural lower secondary pre-vocational school-based programmes and upper secondary VET programmes. Research on relevant factors and possibilities for governance]. Ede/Rotterdam: AOC Council/Strix Aluco - Research \& Innovation.

Van den Berg, N., Nova, B., \& Potiek, S. (2017). Doorstroom in de groene beroepskolom [Transition in the green vocational column]. Den Haag: NRO.

Watson, D. (2006). New labour and higher education. Perspectives: Policy and Practice in Higher Education, 10, 92-96.

Wheelahan, L. (2008). Neither fish nor fowl: The contradiction at the heart of Australian tertiary education. Journal of Access Policy and Practice, 5(2), 133-152.

Winters, A. (2012). Career learning in vocational education: Guiding conversations for career development. Leuven: KU Leuven.

Dr. Harm J.A. Biemans is associate professor at the Education and Learning Sciences group of Wageningen University \& Research. His research concentrates on competence development of (future) professionals and design and effects of corresponding learning environments.

Ing. Hans (J.B.A.) Mariën is researcher at IVA Education, a research institute at Tilburg University with a focus in the field of education research. His research interests focus on school-to-work transition (mainly in higher education) and learning performance at different levels of education.

Erik Fleur M.A. is researcher for the Dutch Department of Education, Culture, and Science. His research interests focus on transitions within the educational system and the relations between vocational and higher education. 
Tanya Beliaeva MSc is data scientist at the Executive Agency for Education (DUO), Department of Education, Culture, and Science. She does research on education pathways of Dutch students from primary education to higher education.

Jan Harbers MSc is educational developer at Terra, a VET institute in the agricultural domain. His research interests focus on the design of continuing learning pathways and effective transitions between successive educational levels. 